\title{
Where do public house managers come from? Some survey
}

evidence.

Dr Alistair Mutch

Principal Lecturer, The Nottingham Trent University

Department of Finance and Business Information Systems, Burton Street, Nottingham, NG1 4BU

Telephone: 01158484206

Fax: $\quad 01159486512$

Email:_ alistair.mutch@ntu.ac.uk

\section{Abstract}

There is little evidence about British public house managers, despite an increase in their relative importance. This article outlines some key issues and reports on the results of a survey of managers in one region of a large leisure retail company. The evidence points to a divergence between married couples and single managers. The former are more likely to have come from a manual working class background with relatively low levels of formal education. A trend towards younger, higher qualified managers from a wider range of social backgrounds is discernible. The extent to which companies in the industry use such evidence in their decision making is questioned.

Key words: public house management; leisure retail management.

\section{INTRODUCTION}

The high streets of Britain bear testimony to significant changes in the way in which public houses are run. Behind the rash of theme pubs lies a move away from ownership or tenancy towards the employment of salaried house managers (Mutch, 2000a). Some major national companies now only operate managed houses and since the 1970s there has been a relative increase in the numbers of salaried house mangers. 
There are a number of factors behind this. The decline in the absolute number of houses has affected smaller, tenanted houses disproportionately. At the same time, the development of larger houses requiring high capital inputs has tended to favour the use of managers. The Beer Orders which followed the finding of a 'complex monopoly' by the 1989 Monopolies and Mergers Commission report forced the divestment of houses by the large brewers (Monopolies and Mergers Commission, 1989). This not only saw them tending to retain the larger, more profitable, managed houses, but also saw the emergence of many new players in the market. These 'leisure retailers' often tended to operate with particular brand concepts which required management to tight specifications. This adherence to brand specifications has also had a significant influence on larger organisations, as they have attempted to define and address market segments more tightly (Williams, 1998). This article explores the impact of these trends on the type of people who manage these houses.

The work reported on here has its origins in investigations into the use of information by house mangers. During this it was found that there were many assertions about the background and characteristics of mangers, but not much evidence. This was true not only within the organisations involved in the investigations, but also in the wider literature. The rather restricted volume of literature on the subject of the public house tends to make little of the distinction between, for example, tenants and house managers (Smith, 1981). Whilst recent work on Bass has managed houses as its focus and some discussion of the manager's role, it is more centrally concerned with processes of organisational change (Preece, Steven and Steven, 1999). However, in the presentation of some limited evidence on the backgrounds of house managers, the authors do make the suggestive comment that house management has been a “stairway to the stars for the unskilled” (Preece, Steven and Steven, 1999: 178). This 
reinforces the pattern evident in the historical account but suggests the need for a more detailed investigation of the background of house managers. Accordingly, this article seeks to provide some evidence drawn from a survey of one group of managers. It reviews some of what we know about managers and tenants before introducing the nature of the evidence presented, which combines data from the survey with interview material. This then leads into the main focus of the article, which is on the sort of people who become managers and some of their characteristics. In particular, the class and prior occupational backgrounds of managers, together with their educational qualifications, are explored. This raises questions about the continued availability of a route into management based on life experience, given the trend towards younger, more qualified managers. The conclusion considers the implications of these findings in two dimensions. Within the industry, it questions the extent to which informed decisions about recruitment are made which recognise these trends. At a broader level, it places them within the context of shifts in the nature of the workforce and the narrowing down of opportunities for those who have not acquired the relevant credentials.

\section{BECOMING A HOUSE MANAGER}

The slow development of managerial systems from the mid-nineteenth to the midtwentieth century saw the assimilation of managers to the dominant pattern of tenancies (Mutch, 2000b). Tenants were generally married couples with the man holding the licence (licensing justices tending only to accept the widows of tenants as single tenants) (Jennings, 1995). The house was usually taken as a change of occupation in the mid to late 30s, with occupations such as the services or sports 
being common routes to tenancy. The assimilation of management to this pattern was confirmed in the early 1970s by Hyde (1974), whose small sample found no difference between managers and tenants in an age of entry of 36.6 years. There were no single female managers and Hyde's interviewees were all male, with few formal educational qualifications. There was some, but limited movement between tenancy and management, although management was considered as rather less well rewarded. However, there have clearly been major changes in both society and trade since Hyde wrote: what have these changes meant for managers?

The evidence presented below was derived from a questionnaire completed in December 1999 by house managers in one region of a national leisure retail organisation. This region covered the eastern side of England, from Cambridge in the south to the Scottish border. The company, in common with many others, classified its pubs according to a number of dimensions, one of which was whether houses were predominantly concerned with food ('food-led') or fitted the more traditional pattern of houses ('wet-led'). The former were excluded from this survey, as the demands on managers here are arguably more similar to those on restaurant managers. 231 questionnaires were sent through the company’s internal mail system to all the wetled managers and 99 usable responses were received, a response rate of 43 per cent. This high response rate was in part thanks to the support of the company in organising distribution, but also the relatively simple nature of the questionnaire. This was designed to collect some basic data about age, length of time as manager, educational qualifications, prior experience and occupational background. However, this requires some discussion of the limitations of the evidence presented. 


\section{$\underline{\text { SURVEY LIMITATIONS }}$}

Of course, even the simplest questions require interpretation or can give misleading results. For example, one respondent to the pilot questionnaire indicated that both he and his partner came from skilled working class backgrounds (as judged by father's occupation, discussed below). However, when interviewed subsequently, he described his route into house management as follows:

Yes, what it was, I was a joiner as a kid, numerous jobs in joinery, doubleglazing, things like that, decided to come into the pub trade. Always wanted the pub trade because of family. My family has been around it.

It transpired that all of this manager's family, apart his parents, had run public houses. Questionnaires cannot capture this rich data, but it is still felt that they can give us some guidance as to the main contours of the landscape. This guidance is supplemented in this account by material drawn from a series of interviews with house managers which formed part of a broader investigation into patterns of information use.

A further issue is the use of occupation as an index of social class (Wright, 1997). The links between occupation and social class are complex and simple responses on a questionnaire can be misleading. An occupation involving self-employment or control of resources can give a qualitatively different experience to one which involves an employment relationship. However, the value in using standard classifications is that we have readily available points of comparison. Using occupation is a reasonably familiar exercise which doesn't involve excessive effort on the part of the respondent. 
The measure used in this questionnaire to assess social class background was father's occupation. Again, there is a considerable debate about the distorting impact of such a simple measure. Clearly, changes in employment patterns make measures of a household's class status of more potential value. However, this is to introduce a further layer of complexity. Finally, it is not necessarily the case that respondents know the detail involved in a particular occupation. A response like 'local authority' might either reflect the full extent of knowledge, or may encapsulate hidden assumptions (assumptions perhaps nicely summarised in one response of 'sparky' taken to mean electrician!) These assumptions are important in the two dominant occupations given, those of miner and steelworker, which reflect the nature of much of the area covered by the survey. Such simple labels can hide considerable differences in job content, with, for example, miners being classified as an occupation under the semi-skilled manual group but face workers being in the skilled manual category. For the purpose of this analysis, miners have been included in the semiskilled group, steelworkers in the unskilled group, fir this is where the Standard Occupational Classification would place those so recorded. However, it is entirely possible that this is to under-record the entries in the skilled and semi-skilled groups respectively.

Finally, there is need for caution in assessing the significance of results on the background of managers. The issue is whether the results are measuring the characteristics of those who are likely to enter house management or the selection criteria of employing organisations. In a situation where there is rapid industrial change with a potentially high demand for management positions, those who become managers may reflect the sort of people that organisations want to employ, rather than 
the ranks of those who aspire to be managers. This needs to be seen in the development of more systematic, structured approaches to the recruitment by larger companies (Lunn, 1987). However, even with these words of caution in mind, the survey results still point to some interesting patterns which help to supplement material gathered in other ways.

\section{THE SURVEY RESULTS}

Of the respondents, 63.7 per cent were from married couples, a figure which matches almost identically the number estimated to be in the population of those surveyed. Of the single respondents (single, that is, as far as responsibility for running the house was concerned) 19 per cent were male as compared to 22 per cent in the population, with a similar, balancing difference in the female figures. The survey respondents, therefore, might be taken to match the population profile well. One of the questions of interest, in the light of Hyde's data presented above, is the age of taking the house. A mean cannot be calculated, as respondents were asked to indicate where they fell in age bands, but this data still allows some conclusions to be drawn. Not surprisingly, the married couples were older at the time of the survey than their single counterparts, but the pattern of age on entry bore more similarities. In both cases the largest single group, more than 25\%, were between 26 and 30 .

Take in table I about here

In the married group female partners tended to be younger, so this could skew the pattern. Of course, such data does not indicate who might have been the prime mover in the shift into management. Even if the husband took on the position of figurehead, the wife might have a considerable influence which is hidden by the questionnaire. 
One male manager confessed that "The honesty is I never wanted a pub. My wife was interested in pubs.” This manager was a self employed roofer who became friendly with an area manager through being the secretary of the darts and domino league. The combined pressure of his wife asnd the area manager resulted in his taking over a house, albeit reluctantly. "For the first six months,” he recalls, I could have finished any day of the week. You know I was hemmed in. I'd always worked outside. I just felt claustrophobic if you like.” In this case the prime mover appears to have been the woman, and so taking an average age of the couple on entry to management appears to be valid.

However, the difference between the two groups lies in the 28 per cent of single managers who report becoming managers between the ages of 21 and 25 (slightly higher with females than males.) Two trends emerge: amongst all managers, entry is likely to be at a younger age than when Hyde was interviewing his managers, and this is exaggerated amongst single managers. This is not to argue that managers do not still follow the 'classic' pattern, but that only a third of married managers and one fifth of single managers had followed such a course.

What had these managers done before entering the trade? One area of interest was the extent to which managers had worked their way up through the ranks of bar staff, or had entered from entirely separate occupations. In addition, it was of interest to see whether managers moved in from tenancy. The latter route can be dealt with fairly quickly. In the whole sample, nearly seven per cent had managed a house for another company, with another six per cent having been landlords, either within the company or elsewhere. Entry 'from the trade', whilst not uncommon, was only a marginal route in. 
Take in table II about here

Much more prevalent was an entirely distinct occupation. Over half of the sample (57 per cent of married couples, 42 per cent of single managers) had this background. However, the sample diverged when it came to those who had whose previous job had been as bar staff. Fully 41 per cent of single managers (as compared to 17 per cent of one or both partners in married couples) had previously worked for the company behind the bar. This figure was 48 per cent for female single managers, a figure in line with the $50 \%$ reported by Preece et al for all female managers (although their figures make no distinction between married and single managers) (Preece, Steven and Steven, 1999: 179). There is a clear trend here for more managers to be 'home grown', in line with company aspirations to reduce staff turnover and promote the notion of a career ladder.

Other occupations were clearly less important for these managers, but central to the careerrs of most managers. When we look at the occupations followed, the figures again diverge, with managerial occupations (typically in retail) being prevalent among single managers, but skilled manual and non-manual working class occupations dominating amongst the married couples. However, what is interesting is that the pattern shows a close correlation (.95) with the social class groupings recorded in the 1991 census (Office of Population, Censuses and Surveys, 1994). Whilst this is not strictly speaking a totally valid comparison, as occupations recorded were at different time periods, the respondents in this sample show a close similarity to the profile of groupings across the occupied population of the country as a whole. This might be to conceal clusters of occupations within these very broad groupings. One that seems to stand out is broadly the construction trades, one in which movement in and out of 
self-employment is relatively easy (Scase and Goffee, 1981). Of course, what questionnaires conceal is the pattern of previous occupations, indicated by the passages noted above and this response to the questionnaire: "worked down the mines, building trades worker, lorry driver.”

Another perspective on those becoming managers can be obtained by looking at the level of qualifications held. Respondents were asked to indicate the highest qualification held and, once again, two patterns emerge.

Take in table III about here

Amongst married couples, the pattern is quite clear of a low prevalence of formal qualifications. 35 per cent had no formal qualifications, with another 45 per cent holding the equivalent of $\mathrm{O}$ levels. The lack of qualifications was strongest amongst the married men, a full 40 per cent of whom had no formal qualifications. Whilst 45 per cent of single managers also had stopped at the O level stage, there was a much higher proportion (a quarter) with a levels or the equivalent. Interestingly, both groups had roughly similar proportions (8.5\% for single, $7.5 \%$ for married) with degrees. Whilst management remains an occupation for those who are changing occupation with significant life experience as their primary qualification, the trend towards a more educated workforce is displayed in this data.

The survey also included material on sources of information and membership of various bodies. Of interest in this context was the continued support for the managers trade union, the National Association of Licensed House Managers (Elkins, 1976). 43 
per cent of the sample were members, despite the continuing decline of the organisation at national level, following de-recognition by the major companies (Preece, Steven and Steven, 1999). The existence of such continuing loyalties confirms the pattern outlined above but warrants further investigation. For the purpose of this discussion, however, the social class background, as measured by father's occupation, of managers is now examined. One of the issues raised above was the extent to which managers came from a 'trade' background. Five per cent of the respondents could be said to come from this background - 3 had fathers who were public house managers, 2 who were landlords and 1 (perhaps stretching the point) a nightclub owner. Once again, this indicates a marginal role for some sort of 'trade succession'. The problems with the eliciting of the father's occupation only are seen with the low representation of social group three (non-manual) with its gender bias in clerical occupations. This means that the relevant comparisons with national this time are with male social class, and these are presented in table IV:

Take in Table IV about here

What is noticeable here is the divergence in background between the married and single managers. In the former group only 16 per cent came from managerial and technical backgrounds, compared to 32 per cent for the single group. Together with the twelve per cent for the professional group this tends to indicate the success that the industry has had in promoting house management as an acceptable occupation for those from these groups. Overall, however, the groups of manual working class occupations remain the most important sources for the respondents as a whole and these are out of proportion to the distribution amongst the male population. The 
caveats about miners and steelworkers made above are important here; redistribution on the basis of further information might well make the skilled group much greater. House management remains a route for those from a working class background with relatively low formal educational qualifications. The interview material can help to illustrate this. A male manager recalls that “ I was well I had quite a few jobs. I was a contractor. I was a doorman. ...No qualifications at all.” His wife then helps him out, adding that, "You've done this work on building sites and foundry. You worked in a foundry didn’t you?” before elaborating on her own career path. “ I was a secretary,” she explains, “ well I was a receptionist secretary for five years and then I left to have a baby. Then I worked in a supermarket on the checkout you know dealing with people.” Interestingly, she also adds that, "But before that I mean I was stood in pubs when I was five helping my mum because my mum used to be a cleaner.” She had then done some part-time bar work but for her husband it was, “ Thirty years of age before I worked in a bar.”

This seems to summarise the 'classic' route into management well. The question that this survey and other evidence raises is the extent to which this is being whittled away. It has been seen throughout the data above that there is a divergence between married couples who enter the trade from unrelated occupations with low formal qualifications and broadly from a skilled working class background and single managers who have higher qualifications and enter the trade as bar staff, perhaps with a broader exposure to managerial jobs from their background.

\section{CONCLUSIONS}


Most of the houses run by these managers are unbranded, 'traditional', outlets. The trends isolated above might be considered to have moved further in branded outlets, especially those aimed at the youth market. It would be wrong to see this as an inevitable process. In our sample, 24 outlets were classified as being predominantly younger venues. Whilst most of those in town centre locations were managed by single managers, and the most common age bracket was 26-30, only 37 per cent of their managers were in fact under 30 at the time of the survey. It is perfectly possible for a venue which aims at young people to be managed by older managers. However, there does seem to be a shift to recruit managers in the image of the customers, a shift which finds a parallel in other interactive service encounters (Thompson, Warhurst and Callaghan, 2000). This, coupled with the efforts of the industry to attract a more educated workforce, particularly graduates, is likely to shift the profile of managers from that identified. However, the full extent of this shift should not be exaggerated. There might well be the conversion of town centre outlets to this model, but this might not apply to the entire management cohort. One manager of a branded outlet argued that, “I don’t know, the younger ones don’t seem to have as much energy, as much enthusiasm.” His argument here related not to performances on particular occasions, but to the longer term. “ Now some do,” he accepted, “I’m not going with the whole, I'm going with the odd ones and they don't seem to, you know to last. They don’t seem to go the full way, full distance.” Obviously this comment from a 38-year-old manager bears the bias of his own background and experience. However, we should perhaps not see the triumph of brands and the credentialled manager as inevitable. What this does raise is the importance of considering the impact of such trends on the broader workforce and the implications for educational development. Thompson et al, for example, question the emphasis of vocational education on areas 
such as information technology training, arguing that, “it needs to address more seriously the social competencies that contemporary work requires” (Thompson, Warhurst and Callaghan, 2000: 137). Whilst this is an important debate, for the purpose of this article two issues seem worth discussing. One is the impact of the trends discussed within employing organisations, with specific reference to the methods used to monitor their extent. The second is the effect on the 'stairway to the stars’ that Preece at al allude to, which has broader implications.

The first question is concerned with the way in which this sort of evidence is used within the industry when making decisions about recruitment. In this organisation there was no central database of educational qualifications and, indeed, the collection of such data was hampered by organisational processes. If a manager had worked been recruited in the house and had worked their way up their qualifications, if recorded, would have been stored in the house and would not be available centrally. Yet decisions were being made about the sort of people who ought to be recruited which might be thought to have benefited from such evidence. That is, central human resource decisions were tending to favour increased graduate recruitment on the basis of very little evidence that such recruits were indeed more effective. This raises important questions about the nature of knowledge in organisations which are particularly pertinent in the context of current debates about 'knowledge management'. In this case, it reflects the relatively marginal role of human resource departments in organisations, with decisions taken on marketing or operational grounds subsequently having considerable impacts on workforce composition. Of course, in many areas of life actions and theories are underdetermined by data. However, the emergent consequences of the strategies adopted by organisations can 
have considerable consequences for workforce composition when their aggregate impact is realised.

In this case, the impact is on the possibility of those lacking formal educational qualifications acquiring jobs broadly described as 'managerial'. Public house management has typically been one such route, allowing those with few or no formal qualifications but considerable life experience to succeed in establishing a new career. The result of the trends described above is to place still more weight on formal educational qualifications and on the acquisition of them at the 'right' time, that is when they are offered through the conventional educational route of secondary and tertiary education. What might be interesting here is to set this in the context of Basil Bernstein's claim, expressed in 1971, that "the nineteenth century required submissive and inflexible man [sic], whereas the late twentieth century requires conforming but flexible man” (Bernstein, 1971: 225). He is referring here to the nature of the division of labour and its impacts on educational requirements. Simple methods of production, he argued, require specific skills learned through experience which are deployed following strict orders. In the modern division of labour, independent thought is required at work, but within clear boundaries. Such thought is required to interpret the ever-increasing range of information produced to monitor and control operations. This tends towards the employment of those who possess the qualifications, marked by formal credentials, to use such information. However, they also, according to Bernstein, accept the limitations of their role and don't move on to criticise the boundaries within which they work. Those who lack the formal credentials may possess the resources, based on their life experience, to challenge these boundaries. Such challenges, of course, might be necessary to devise new strategies or to test the limits of existing ones. However, the contradiction here is that, whilst organisations 
may be able to mould younger recruits to be the "conforming but flexible" managers who carry out schemes increasingly laid down by central marketing departments, do such managers have the qualities of commitment and persistence engendered by life experience? In turn, the rejection of life experience can restrict the horizons and the possibilities for those who, for a variety of reasons, have not followed the 'correct' educational path.

\section{Acknowledgements}

The fieldwork on which this paper is in part based was enabled by a grant from the ESRC Small Awards fund, reference 00022 2881. Thanks are also due to the many staff in the company who enabled the survey to take place and the referee for very helpful and constructive suggestions.

\section{REFERENCES}

Bernstein, B (1971), Class, Codes and Control, Volume 1, Routledge and Kegan Paul, London.

Elkins, T. (1976), Mild and Bitter, Sir: the story of N.A.L.H.M., National Association of Licensed House Managers, London.

Hyde, P. (1974), The occupational role of publican, Unpublished MPhil, University of Kent.

Jennings, P. (1995), The Public House in Bradford, 1770-1970, Keele University Press, Keele.

Lunn, T. (1987),”A scientific approach to successful selection”, Personnel Management, December pp. 43-45. 
Mutch, A. (2000a), “Trends and tensions in UK public house management”, International Journal of Hospitality Management, in print.

Mutch, A. (2000b), “An early twentieth century information system”, Journal of Managerial History, in print.

Office of Population, Censuses and Surveys, (1994), 1991 Census: Economic Activity, Vol. 2, HMSO, London.

Preece, D., Steven, G.and Steven, V. (1999), Work, Change and Competition: Managing for Bass, Routledge, London.

Scase, R.and Goffee, R. (1981),’'Traditional' Petty Bourgeois Attitudes: the Case of Self-employed Craftsmen”, Sociological Review, Vol 29 No 4, pp. 729-747.

Smith, M. (1981), The Pub and the Publican: A Participant Observor Study of a Public House, Centre for Leisure Studies, University of Salford, Salford.

The Monopolies and Mergers Commission, (1989), The Supply of Beer. A report on the supply of beer for retail sale in the United Kingdom, Cm 651 HMSO, London. Thompson, P., Warhurst, C. and Callaghan, G. (2000), “Human capital or capitalising on humanity? Knowledge, skills and competencies in interactive service work” in Prichard, C., Hull, R., Chumer, M. and Willmott, H. (eds.) Managing Knowledge: Critical Investigations of Work and Learning, Macmillan, Basingstoke.

Williams, A. (1998),’The postmodern consumer and hyperreal pubs”, International Journal of Hospitality Management, Vol 17, pp. 221-232.

Wright, E. O. (1997), Class Counts: Comparative Studies in Class Analysis, Cambridge University Press, Cambridge. 